\title{
Erratum to: Analysis of Prognostic Factors in Extraosseous Ewing Sarcoma Family of Tumors: Review of St. Jude Children's Research Hospital Experience
}

W. Shannon Orr, $\mathrm{MD}^{1,2}$, Jason W. Denbo, $\mathrm{MD}^{1,2}$, Catherine A. Billups, $\mathrm{MS}^{3}$, Jianrong $\mathrm{Wu}_{\mathrm{u}} \mathrm{PhD}^{3}$, Fariba Navid, $\mathrm{MD}^{4}$, Bhaskar N. Rao, $\mathrm{MD}^{2}$, Andrew M. Davidoff, $\mathrm{MD}^{1,2}$, and Matthew $\mathrm{J}$ Krasin, $\mathrm{MD}^{5}$

${ }^{1}$ Department of Surgery, University of Tennessee Health Science Center, Memphis, TN; ${ }^{2}$ Department of Surgery, St. Jude Children's Research Hospital, Memphis, TN; ${ }^{3}$ Department of Biostatistics, St. Jude Children's Research Hospital, Memphis, TN; ${ }^{4}$ Department of Oncology, St. Jude Children's Research Hospital, Memphis, TN; ${ }^{5}$ Department of Radiological Sciences, St. Jude Children's Research Hospital, Memphis, TN

ERRATUM TO: ANN SURG ONCOL (2012) 19:3816-3822 DOI 10.1245/S10434-012-2458-4

In the original publication, the first author's surname is captured incorrectly. The correct name is Orr, W. Shannon.

The online version of the original article can be found under doi:10.1245/s10434-012-2458-4.

(C) Society of Surgical Oncology 2013

Published Online: 11 May 2013

W. S. Orr, MD

e-mail: worr1@uthsc.edu 